\title{
Coneixement científic \\ a l'abast de tothom: \\ creació d'un repositori \\ obert sobre l'impacte \\ social de la recerca
}

\author{
Joan Cabré Olivéa \\ Data de defensa: 23/06/2015
}

Paraules clau: impacte social, accés obert, repositori.

\begin{abstract}
Resum
La tesis doctoral té com objectiu aportar coneixement i elements al debat actual sobre com millorar la qualitat de la recerca internacional, i més concretament en l'àmbit de les ciències socials i humanitats, a partir de la creació d'un repositori obert centrat en l'avaluació de l'impacte social de la recerca. Per fer-ho s'han elaborat dues preguntes de recerques que han sigut les que han orientat la recerca realitzada per l'elaboració de la tesis:
\end{abstract}

1. Recollir i analitzar experiències d'accés obert a la informació.

2. Contribuir al retorn del coneixement, fruit de la recerca, a la ciutadania a través de la creació un repositori obert sobre impacte social de caràcter internacional.

Aquesta proposta s'emmarca en el debat sorgit de l'estratègia Europa 2020 que té com objectiu continuar amb l'estratègia de Lisboa elaborada el 2010 en resposta a la situació de crisis a nivell mundial i contribuir a la construcció de societats i sistemes educatius eficients que contribueixin a la millora social del conjunt de la ciutadania europea. És aquí on les ciències socials i humanitats tenen un paper primordial si no volen perdre l'oportunitat de mostrar les seves aportacions a la transformació i millor social.

La comissària de la Unió Europea per a la Recerca, Innovació i Ciència, Máire Geoghegan-Quinn, va suggerir el gener de 2014 en una sèrie de conferències per

\footnotetext{
a Universitat Rovira i Virgili
} 
introduir el programa Horizon 2020 que el nou programa marc de recerca suposava un "canvi de paradigma". Constituint un total i nou punt de partida per la Unió Europea i orientat al màxim impacte per a la societat europea. El propòsit del programa Horizon 2020 no és més que lliurar a la ciutadania els resultats de la recerca que suposaran una diferència en la vida de les persones.

Ara les demandes també venen des de baix, des de la pròpia ciutadania i de tots els sectors socials. Contribuint així als debats i argumentació relacionats amb els valors i els objectius de la ciència i la política. La pràctica científica és d'interès públic ja que més que mai pot generar conseqüències a vegades inesperades i perquè la política d'investigació també està condicionada per riscos i la pressió dels moviments socials (Beck, 2002). És en aquest moments, quan més que mai és necessari un procés dialògic de recerca, on estiguin inclosos de forma igualitària els anomenats "end-users" i els diferents grups d'interès (polítics, socials, etc.).

És en aquest marc on va ser aprovat el projecte IMPACT-EV: Evaluating the impact and outcomes of EU SSH research (2014-2018) del VII Programa Marc de la Comissió Europea, dirigit pel professor Ramón Flecha de la Universitat de Barcelona.

El principal objectiu del projecte IMPACT-EV és definir el futur sistema de monitoratge i avaluació de la política científica i impactes social de la recerca en Ciències Socials i Humanitats a Europa. I és dins d'aquest objectiu on s'emmarca la meva tesis doctoral a través de la meva col•laboració en el desenvolupament d'un repositori obert d'impacte social (SIOR). SIOR és el primer registre obert d'impacte social que connecta resultats de recerca que demostren haver obtingut una millora social.

Un producte resultat de la recerca que lliga molt amb el debat actual sobre l'accés obert i la ciència oberta. Un debat que està plantejat la necessitat que els resultats de recerques, que a més han estat finançades amb l'erari públic sigui a nivell local, nacional o internacional, estigui a l'abast de tothom de forma oberta i gratuïta. La idea de que el coneixement científic estigui a l'abast de tothom com a dret, com a forma democràtica i dialògica de funcionar i com a una manera de contribuir a la millora de la vida de les persones i de la societat en general. Aquesta nova forma de funcionar és ja una realitat, que està canviant no només la forma de presentar la recerca si no que està suposant un canvi cultural i social que està qüestionant les formes tradicionals de comunicar i avançar en recerca (Nielsen, 2012; Willinsky, 2001; Willinsky, 2005a; Willinsky, 2005b).

A nivell metodològic, cal dir que la tesis ha tingut una orientació metodològica comunicativa (Gómez et al. 2006; Gómez, Puigvert \& Flecha, 2011) i que persegueix mostrar el procés inicial de creació d'un repositori obert que permeti la mesura de l'impacte social de les recerques en Ciències Socials i Humanitats. És una recerca aplicada però que també ha partit d'una explotació bibliogràfica teòrica molt sòlida a través de l'anàlisi i sistematització de les principals experiències d'accés obert actuals i la realitzada a través del projecte del VII Programa Marc de la Comissió Europea: IMPACT-EV (Evaluating the impact and outcomes of European Social Sciences and Humanities research). A aquesta s'afegeix la realització de 3 entrevistes (una a partir de 
fonts secundàries) a experts/es en l'àmbit d'impacte social i sistemes d'avaluació i accés obert.

Els resultats de la tesis són una aportació al debat actual sobre, per una banda, la necessitat de poder mesurar l'impacte social de les recerques i, per altra banda, de tenir eines $\mathrm{i}$ indicadors universals que permetin que aquesta mesura sigui útil tant per als investigadors/es com a la ciutadania en general que vol tenir accés de forma fiable al coneixement que s'està construint des de la recerca. És aquí on el desenvolupament d'un repositori obert d'impacte social suposa una aportació única que donarà resposta a aqueta necessitat, millorant la recerca i l'impacte de la mateixa en la millora de la societat. 